\title{
Inspiratory muscle function, dynamic hyperinflation and exertional dyspnoea in pulmonary arterial hypertension
}

\author{
To the Editor:
}

Despite a preserved forced expiratory volume in $1 \mathrm{~s}\left(\mathrm{FEV}_{1}\right) / \mathrm{vital}$ capacity (VC), patients with idiopathic or heritable pulmonary arterial hypertension $(\mathrm{PAH})$ may dynamically decrease their inspiratory capacity (IC) during cycle exercise (i.e. dynamic hyperinflation) [1-3] and this could increase exertional dyspnoea [1, 3 , 4]. Little information is currently available about whether the reduced IC during cycle exercise is related to respiratory mechanics abnormalities or to impaired inspiratory muscle function (fatigue or weakness). The aim of this study was to evaluate the relationship between inspiratory muscle activity, dynamic changes in IC and the intensity of dyspnoea in $\mathrm{PAH}$ patients undergoing incremental symptom-limited cardiopulmonary cycle exercise test (CPET).

We studied 10 consecutive lifelong nonsmoking clinically stable patients with idiopathic or heritable PAH [1], diagnosed according to the current evidence-based guidelines [5], with a normal body mass index, no spirometric evidence of obstructive ventilatory defect [6] and no other concomitant diseases [1]. Five patients (four female/one male, mean $\pm \mathrm{SD}$ age $45 \pm 6$ years, $\mathrm{FEV} 1 / \mathrm{VC}=103 \pm 4 \%$ predicted) reduced their IC dynamic hyperinflation during exercise (hyperinflator group (PAH-H)), whereas 5 age-and sex-matched $\mathrm{PAH}$ (four female/one male; $41 \pm 14$ years; $\mathrm{FEV} 1 / \mathrm{VC}=117 \pm 6 \%$ predicted) did not (non-hyperinflator group (PAH-NH)). The research was carried out in accordance with the principles outlined in the Helsinki Declaration. The subjects gave their informed consent to participate, and the study received the approval of the appropriate local review authority (Comité de Protection des Personnes de Paris Ile de France VI, Groupe Hospitalier Pitié-Salpêtrière, Paris, France, CPP/33-11 - ID RCB: 2011-A00326-35).

Subjects performed pulmonary function testing and an incremental CPET, both as previously described [1], with the following detailed oesophageal $\left(P_{0 e s}\right)$ pressure-derived respiratory mechanical measurements: static compliance (CLst), and maximal inspiratory sniff pressure (Poes,sniff) pre-exercise at rest and immediately at end-exercise $[7,8]$. Operating lung volumes derived from IC manoeuvres were measured at rest, every second minute during exercise, and at end-exercise [1, 7-9]. During IC manoeuvres, dynamic peak inspiratory Poes (Poes,IC) was recorded [7]. Intensity of dyspnoea was rated using the modified 10-point Borg scale at rest, every minute during exercise and at peak-exercise [7]. Data were analysed and compared at rest, at common standardised work-rates $(20,40$ and $60 \mathrm{~W})$ and at peak-exercise using t-tests with Bonferroni adjustments for multiple comparisons.

Pulmonary function variables did not differ between the two groups except for the forced expiratory flow at $75 \%$ of the forced vital capacity, which was reduced in PAH-H compared with PAH-NH (mean \pm SD $31 \pm 10$ versus $90 \pm 13 \%$ predicted, respectively; $\mathrm{p}=0.0003$ ) [1].

The cardiometabolic and ventilatory responses to CPET were superimposed between PAH-H and PAH-NH [1]. IC decreased progressively throughout CPET in PAH-H by $0.4 \mathrm{~L}$, whereas it increased in PAH-NH by $0.3 \mathrm{~L}$ on average (fig. 1). Mean \pm SD Poes,IC did not change significantly at any stage of exercise either within and between the two groups (fig. 1), for PAH-H versus PAH-NH the data were as follows: at rest, $-29.6 \pm 5.2$ versus $-33.4 \pm 8.5 \mathrm{cmH}_{2} \mathrm{O}$; at $20 \mathrm{~W},-29.0 \pm 5.4$ versus $-33.1 \pm 8.5 \mathrm{cmH}_{2} \mathrm{O}$; at $40 \mathrm{~W},-29.2 \pm 5.0$ versus $-34.2 \pm 8.3 \mathrm{cmH}_{2} \mathrm{O}$; at $60 \mathrm{~W}$ (iso-WR), $-30.2 \pm 4.4$ versus $-34.4 \pm 8.1 \mathrm{cmH}_{2} \mathrm{O}$; at peak, $-30.8 \pm 6.0$ versus $-33.6 \pm 9.2 \mathrm{cmH}_{2} \mathrm{O}$.

Dyspnoea intensity was greater in $\mathrm{PAH}-\mathrm{H}$ at a standardised work rate of $60 \mathrm{~W}$ (iso-WR) (mean $\pm \mathrm{SD}$ $4.8 \pm 1.3$ versus $2.7 \pm 1.0$ Borg units, respectively; $\mathrm{p}=0.01)$ and at peak-exercise $(7.6 \pm 1.1$ versus $5.2 \pm 1.3$ Borg units, respectively; $\mathrm{p}=0.01$ ) compared with $\mathrm{PAH}-\mathrm{NH}$ [1].

Compared with pre-exercise, mean \pm SD end-exercise CLst and Poes,sniff did not differ within the two groups, as follows. Pre- versus end-exercise in PAH-H: CLst $0.24 \pm 0.05$ versus $0.25 \pm 0.05 \mathrm{~L} \cdot \mathrm{cmH}_{2} \mathrm{O}^{-1}$; and Poes,sniff $-70.8 \pm 10.7$ versus $-71.8 \pm 12.6 \mathrm{cmH}_{2} \mathrm{O}$. Pre- versus end-exercise in $\mathrm{PAH}-\mathrm{NH}$ : CLst $0.13 \pm 0.01$ versus 0.14 $\pm 0.02 \mathrm{~L} \cdot \mathrm{cmH}_{2} \mathrm{O}^{-1}$; Poes,sniff $-67.0 \pm 17.2$ versus $-69.2 \pm 20.8 \mathrm{cmH}_{2} \mathrm{O}$. Based on the American Thoracic 

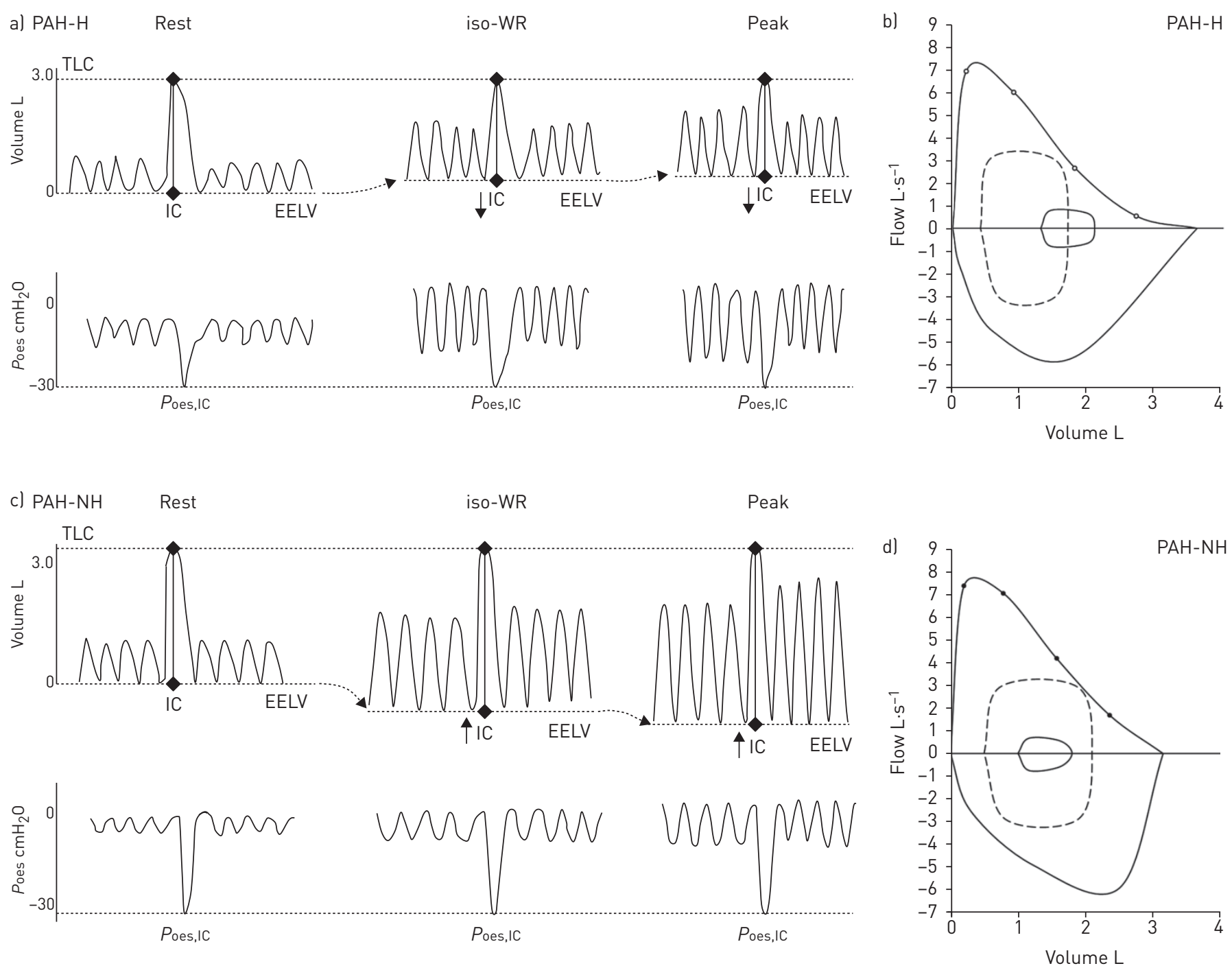

FIGURE 1 Tracings of lung volume (volume) and oesophageal pressure (Poes) from inspiratory capacity (IC) manoeuvres taken during resting breathing, at 60 W (iso-WR) and peak-exercise from a) one representative pulmonary arterial hypertension (PAH) patient who reduced IC (or increased end-expiratory lung volume $($ EELV)) during exercise (PAH-H) and c) one who increased IC (or reduced EELV) (PAH-NH). Please note that, regardless of changes in IC during exercise, dynamic peak inspiratory Poes recorded during IC manoeuvres (Poes,IC) is remarkably preserved in both a) PAH-H and c) PAH-NH. Maximal and tidal flow-volume loops (average data) are shown at rest and at peak-exercise in b) PAH-H and d) PAH-NH. Tidal flow-volume loops are provided at rest (solid line) and at peak-exercise (dashed line). Note a significant decrease in dynamic IC during exercise in PAH-H compared with PAH-NH. TLC: total lung capacity.

Society/European Respiratory Society statement on respiratory muscle testing [10], which clearly states that values of maximal Poes,sniff numerically greater than $-70 \mathrm{cmH}_{2} \mathrm{O}$ (in males) or $-60 \mathrm{cmH}_{2} \mathrm{O}$ (in females) are unlikely to be associated with significant inspiratory muscle weakness, only one female PAH patient had values outside this "normal range" (belonging to the "non-hyperinflator" group) presenting with a maximal Poes,sniff of $-47 \mathrm{cmH}_{2} \mathrm{O}$ before exercise and of $-48 \mathrm{cmH}_{2} \mathrm{O}$ right after exercise. All the other patients fell within the range of normalcy.

Of note, $50-60 \%$ of the variance of the difference between Borg ratings of dyspnoea at rest and at $60 \mathrm{~W}$ was accounted for by changes in dynamic IC.

The novel findings of this study are as follows: 1) PAH patients had preserved inspiratory muscle function regardless of changes in dynamic IC during cycle exercise; 2) IC manoeuvre is reliable in evaluating dynamic hyperinflation during CPET in PAH; 3) dyspnoea intensity was increased in PAH-H and was explained to great extent by the reduction of IC during cycle exercise compared with PAH-NH.

Both PAH-H and PAH-NH groups were young, non-smoking, clinically stable patients, perfectly matched in terms of anthropometric characteristics and resting haemodynamics. They had normal FEV1/VC ratios, nonetheless five of them reduced their IC during exercise while the remainder did not $[1,2]$. 
A dynamic decrease in IC during exercise may either reflect a true dynamic hyperinflation or an impaired inspiratory muscle performance (weakness/fatigue), which would prevent $\mathrm{PAH}$ patients from being able to generate an inspired volume during cycle exercise close or equal to the total lung capacity (TLC) volume at rest. In a previous study we demonstrated that TLC does not change during exhaustive cycle exercise [1]. In the current study we assessed the reliability of IC manoeuvres by comparing dynamic peak inspiratory Poes values during IC manoeuvres, and we clearly demonstrated that Poes,IC values were remarkably preserved during exercise and independent of exercise intensity and ventilation (fig. 1). The contention that PAH patients were able to inspire to a lung volume close or equal to TLC was bolstered by the evidence that end-exercise CLst was remarkably preserved compared with pre-exercise CLst, suggesting that the elastic recoil pressure of the lung does not change during exercise in $\mathrm{PAH}$, as it has been shown in healthy [11], chronic obstructive pulmonary disease [12] and congestive heart failure [13] individuals during exercise.

IC would potentially be altered only when "severe" inspiratory muscle weakness/fatigue occurs. Although inspiratory muscle dysfunction has been suspected in PAH patients at rest $[14,15]$, mostly in severely compromised PAH attending for pulmonary transplantation [16], the contribution of inspiratory muscle weakness/fatigue to the decreased IC can reasonably be ruled out in our PAH-H patients: inspiratory muscle strength was preserved, as highlighted by the preserved Poes,IC during CPET (fig. 1) and the identical Poes,sniff values pre- and post-exercise in both $\mathrm{PAH}-\mathrm{H}$ and $\mathrm{PAH}-\mathrm{NH}$ patients. Differences in technique and disease stage/severity between our PAH population and those of other studies [14-16] may explain the differences between our results and those of other studies.

Last but not least, we confirmed that changes in IC observed during cycle exercise in PAH-H contributed to the greater dyspnoea intensity in $\mathrm{PAH}-\mathrm{H}$ patients compared with $\mathrm{PAH}-\mathrm{NH}$ and are more probably related to abnormalities of respiratory mechanics than to respiratory muscle dysfunction in PAH $[1,3,4]$.

This study is the first to assess the relationship between inspiratory muscle activity, dynamic changes in IC and the intensity of dyspnoea in PAH patients undergoing cycle CPET. Our results clearly indicate that $\mathrm{PAH}$ patients had preserved inspiratory muscle function regardless of changes in dynamic IC during cycle exercise. Dynamic hyperinflation was not related to inspiratory muscle function and contributed to the increased exertional dyspnoea intensity in $\mathrm{PAH}-\mathrm{H}[1,3,4]$.

@ERSpublications

PAH patients had preserved inspiratory muscle function regardless of changes in dynamic IC during cycle exercise http://ow.ly/IoSL5

Pierantonio Laveneziana ${ }^{1,2,3,4,9}$, Marc Humbert ${ }^{5,6,7,9}$, Laurent Godinas ${ }^{4,5,6}$, Barbara Joureau ${ }^{1,2}$, Roxane Malrin ${ }^{4,5,6}$, Christian Straus $\mathbf{s}^{1,2,3}$, Xavier Jaïs ${ }^{5,6,7}$, Olivier Sitbon ${ }^{5,6,7}$, Gérald Simonneau ${ }^{5,6,7}$, Thomas Similowski ${ }^{1,2,8,10}$ and Gilles Garcia ${ }^{4,5,6,10}$

${ }^{1}$ Sorbonne Universités, UPMC Univ. Paris 06, UMR_S 1158, Neurophysiologie Respiratoire Expérimentale et Clinique, Paris, France. ${ }^{2}$ INSERM, UMR_S 1158, Neurophysiologie Respiratoire Expérimentale et Clinique, Paris, France. ${ }^{3}$ AP-HP, Groupe Hospitalier Pitié-Salpêtrière Charles Foix, Service des Explorations Fonctionnelles de la Respiration, de l'Exercice et de la Dyspnée, Paris, France. ${ }^{4}$ AP-HP, Hôpital Universitaire de Bicêtre, Service d'Explorations Fonctionnelles Respiratoires, Centre de Référence de l'Hypertension Pulmonaire Sévère, DHU TORINO "Thorax Innovation", Le Kremlin-Bicêtre, France. ${ }^{5}$ Univ. Paris-Sud 11, Faculté de médecine, Le Kremlin-Bicêtre, France. ${ }^{6}$ INSERM U999, LabEx LERMIT, Centre Chirurgical Marie Lannelongue, Le Plessis-Robinson, France. ${ }^{7}$ AP-HP, Hôpital Universitaire de Bicêtre, Service de Pneumologie et Soins Intensifs Thoraciques, Centre de Référence de l'Hypertension Pulmonaire Sévère, DHU TORINO "Thorax Innovation", Le Kremlin-Bicêtre, France. ${ }^{8}$ AP-HP, Groupe Hospitalier Pitié-Salpêtrière Charles Foix, Service de Pneumologie et Réanimation Médicale, Paris, France. ${ }^{9}$ Both authors contributed equally. ${ }^{10}$ Both authors contributed equally.

Correspondence: Pierantonio Laveneziana, Service d'Explorations Fonctionnelles de la Respiration, de l'Exercice et de la Dyspnée (EFRED), Département "R3S" (Respiration, Réanimation, Réhabilitation, Sommeil), Pôle PRAGUES, Hôpital Universitaire Pitié-Salpêtrière, Assistance Publique-Hôpitaux de Paris (AP-HP), 47-83 Boulevard de l'Hôpital, 75013, Paris, France. E-mail: pierantonio.laveneziana@psl.aphp.fr

Received: Aug 202014 | Accepted after revision: Jan 082015

Support statement: P. Laveneziana was supported by: 1) the Seventh Framework Programme of the European Union, Support for training and career development of researchers (Marie Curie), International Re-integration Grants (IRG), FP7-PEOPLE-2010-RG, grant number: PIRG07-GA-2010-268396-EDPAH; 2) PFIZER Investigator-Initiated Research (IIR), grant number: WS 942458; and 3) HTAP France. Funding information for this article has been deposited with FundRef.

Conflict of interest: Disclosures can be found alongside the online version of this article at erj.ersjournals.com

Acknowledgements: Some of the results of this study were reported in the form of an abstract at the European Respiratory Society International Congress which was held in Munich, Germany, in September 2014: Laveneziana P, Garcia G, Humbert M, et al. Exertional dyspnoea, dynamic hyperinflation and respiratory muscle function in idiopathic pulmonary arterial hypertension (PAHi). Eur Respir J 2014; 44: Suppl. 58, P4890. 


\section{References}

1 Laveneziana P, Garcia G, Joureau B, et al. Dynamic respiratory mechanics and exertional dyspnoea in pulmonary arterial hypertension. Eur Respir J 2013; 41: 578-587.

2 Richter MJ, Voswinckel R, Tiede H, et al. Dynamic hyperinflation during exercise in patients with precapillary pulmonary hypertension. Respir Med 2012; 106: 308-313.

3 Naeije R. Lung mechanics and exertional dyspnea in pulmonary arterial hypertension. Respiration 2014; 88: $16-17$.

4 Laviolette L, Laveneziana P. Dyspnoea: a multidimensional and multidisciplinary approach. Eur Respir J 2014; 43: $1750-1762$.

5 Hoeper MM, Bogaard HJ, Condliffe R, et al. Definitions and diagnosis of pulmonary hypertension. J Am Coll Cardiol 2013; 62: Suppl., D42-D50.

6 Pellegrino R, Viegi G, Brusasco V, et al. Interpretative strategies for lung function tests. Eur Respir J 2005; 26: 948-968.

7 Laveneziana P, Webb KA, Wadell K, et al. Does expiratory muscle activity influence dynamic hyperinflation and exertional dyspnea in COPD? Respir Physiol Neurobiol 2014; 199: 24-33.

8 Laveneziana P, Webb KA, Ora J, et al. Evolution of dyspnea during exercise in chronic obstructive pulmonary disease: impact of critical volume constraints. Am J Respir Crit Care Med 2011; 184: 1367-1373.

9 O'Donnell DE, Revill SM, Webb KA. Dynamic hyperinflation and exercise intolerance in chronic obstructive pulmonary disease. Am J Respir Crit Care Med 2001; 164: 770-777.

10 ATS/ERS Statement on respiratory muscle testing. Am J Respir Crit Care Med 2002; 166: 518-624.

11 Younes M, Kivinen G. Respiratory mechanics and breathing pattern during and following maximal exercise. J Appl Physiol Respir Environ Exerc Physiol 1984; 57: 1773-1782.

12 Yan S, Kaminski D, Sliwinski P. Reliability of inspiratory capacity for estimating end-expiratory lung volume changes during exercise in patients with chronic obstructive pulmonary disease. Am J Respir Crit Care Med 1997; 156: 55-59.

13 Agostoni P, Pellegrino R, Conca C, et al. Exercise hyperpnea in chronic heart failure: relationships to lung stiffness and expiratory flow limitation. J Appl Physiol (1985) 2002; 92: 1409-1416.

14 Meyer FJ, Lossnitzer D, Kristen AV, et al. Respiratory muscle dysfunction in idiopathic pulmonary arterial hypertension. Eur Respir J 2005; 25: 125-130.

15 Kabitz HJ, Schwoerer A, Bremer HC, et al. Impairment of respiratory muscle function in pulmonary hypertension. Clin Sci (Lond) 2008; 114: 165-171.

16 de Man FS, van Hees HW, Handoko ML, et al. Diaphragm muscle fiber weakness in pulmonary hypertension. Am J Respir Crit Care Med 2011; 183: 1411-1418.

\section{Long-term mortality assessment of multidrug-resistant tuberculosis patients treated with delamanid}

\section{To the Editor:}

Multidrug-resistant tuberculosis (MDR-TB) is a serious obstacle to TB control [1]. The disproportionately negative outcomes among patients with drug resistance reflect a strong global need to develop new anti-TB drugs $[2,3]$. Delamanid is a novel anti-TB agent that has recently been approved for the management of MDR-TB patients [4]. Treatment of MDR-TB patients with delamanid in combination with an optimised background regimen for 2 months significantly improved 2-month sputum culture conversion (SCC) by $\sim 50 \%$, in comparison to treatment with placebo plus an optimised background regimen [5]. Additionally, compared to $\leqslant 2$ months of treatment, $\geqslant 6$ months of treatment with delamanid plus an optimised background regimen was associated with higher favourable treatment outcomes (55.0\% versus $74.5 \%)$ and significantly lower mortality $(8.3 \%$ versus $1.0 \%, \mathrm{p}<0.001)$ [6]. While early SCC is recognised as a biomarker in the development of anti-TB drugs [7-9], the impact of early SCC on long-term mortality in MDR-TB patients has only been assessed in retrospective cohort analyses [10-13]. Using updated prospective data from the delamanid development programme, we assessed the association between 2-month SCC and mortality in MDR-TB patients and expanded a previous analysis on the impact of long-term treatment with delamanid on mortality.

The clinical development programme for delamanid involved three consecutive trials: 1) a randomised placebo-controlled trial of 481 patients (Trial 204) for 3 months (2 months delamanid treatment plus 